\title{
A pesquisa do professor da educação básica em questão
}

\author{
Menga Lüdke \\ Pontifícia Universidade Católica do Rio de Janeiro, Departamento de Educação \\ Universidade Católica de Petropólis \\ Giseli Barreto da Cruz \\ Universidade Federal do Rio de Janeiro, Faculdade de Educação
}

\section{Luiz Alberto Boing}

Centro Pedagógico Pedro Arrupe

\section{Focalizando o estudo}

A possibilidade de um professor de escola de educação básica realizar pesquisa é algo que vem suscitando significativo debate no meio universitário, mais até do que no contexto de atuação desse professor. Estudos focados nessa temática são frequentes na literatura acadêmica. Trabalhos como os de Stenhouse (1975), Elliott (1989), Huberman e Gather Thurler (1991), Hammersley (1993), Geraldi et al. (1998), Cochran-Smith e Lytle (1999), Anderson e Herr (1999), Lagemann e Shulman (1999), André (2001), Lüdke (2001a), Zeichner e Nofke (2001), Tardif e Zourhlal (2005), Durand, Saury e Veyrunes (2005), Zeichner e Diniz-Pereira (2005), Lüdke e Cruz (2005) evidenciam o grande interesse e a atualidade desse tema, não apenas entre nós.

Todavia, a questão da identidade da pesquisa do professor da educação básica é algo que se mostra ainda de forma obscura. Dados de pesquisa (Lüdke \& Cruz, 2005) revelam que, na visão de professores e na de seus formadores, essa forma de pesquisar vem sendo considerada importante por todos eles, mas nem sempre assumida como algo imprescindível para o trabalho desse professor, sobretudo em função das condições para a sua realização e divulgação.

Zeichner e Nofke (2001) discutem uma série de aspectos positivos referentes ao tema, especialmente a partir dos conceitos de reflexividade no trabalho do professor, porém não deixam de assinalar fatores que dificultam o desenvolvimento dessa prática, apesar do reconhecimento de sua importância. Entre esses fatores são destacados: a falta de preparação adequada dos professores para o bom desempenho em pesquisa, o que concorre para que seus resultados sejam considerados menos rigorosos do que os obtidos pela pesquisa acadêmica; o valor questionável desse tipo de pesquisa, feita pelo professor, pela dificuldade de generalização a partir da análise de situações restritas; e a falta de tempo disponível para que o professor se dedique a essa prática. A despeito desses fatores negativos, os autores insistem na importância e na irreversibilidade desse novo tipo de pesquisa, a praticada pelo professor, trazendo em seu apoio a contribuição de vários autores conhecidos pelas suas posições assumidamente a seu favor, como Lather (1993, 1986), Roman (1989) e Stevenson (1996), entre outros. 
André (2001) levanta questões muito pertinentes ao analisar os prós e os contra do desenvolvimento de pesquisa pelo professor aos olhos de diferentes autores que têm tratado do assunto. Ela mesma mostra os pontos críticos de uma e de outra posição, mas reconhece claramente a importância da formação do professor, da sua disposição e interesse e finalmente da existência de fatores como tempo, espaço, recursos e estímulos para que o professor possa de fato desenvolver sua dimensão de pesquisador. Num avanço sobre a complexa questão das exigências que cercam o trabalho de pesquisa, segundo autores do ramo, especialmente ao se referirem à importância de produzir conhecimento novo (Beillerot, 1991), André (2001) confirma a importância dessas exigências, mas indaga provocativamente a quem compete decidir ou definir esse conhecimento novo.

Nesse contexto, vem-nos à mente uma interrogação: o que conta como pesquisa? O que é levado em consideração por pessoas encarregadas de atribuir ou não recursos a uma pesquisa apresentada por um professor da educação básica, de aprová-la para apresentação em um encontro científico ou de aceitá-la para publicação em um periódico?

Nossa proposta de estudo voltou-se para um novo sujeito, o avaliador ou o "juiz", como chamaremos aqui, buscando perceber sob que argumentos a pessoa encarregada de orientar o destino do que o professor da educação básica apresenta como sua pesquisa decide sobre ela. Em meio à falta de definição clara de critérios, é bom saber quais são os elementos levados em conta por quem decide se o trabalho merece ou não ser contemplado com o título de pesquisa.

Partindo desses pontos básicos, propusemos um estudo com vários objetivos, destacando-se de modo especial os seguintes: levantar, junto a pesquisadores experientes da área de formação de professores, quais aspectos levam em conta ao avaliarem trabalhos de pesquisa de professores da educação básica. E procurar, a partir dos aspectos indicados por esses julgadores, contribuir para a discussão de critérios amplos que possam abranger os vários tipos de pesquisas realizadas na área de educação em todos os níveis de ensino.
Esse estudo foi realizado no período de 2003 a 2006 pelo Grupo de Estudo sobre a Profissão Docente (GEPROF), com o apoio do Conselho Nacional de Desenvolvimento Científico e Tecnológico (CNPq) e da Fundação de Amparo à Pesquisa do Estado do Rio de Janeiro (FAPERJ). ${ }^{1}$ Neste texto limitamo-nos a explorar alguns dos seus aspectos, priorizando o propósito de destacar o que é levado em conta na hora de decidir sobre pesquisa.

\section{As escolhas dos trabalhos de professores e dos juízes}

Elegemos alguns encontros científicos que costumam reunir professores da educação básica e pesquisadores da universidade como lócus preferencial para localização dos trabalhos almejados. Nossa intenção residia em identificar trabalhos de professores com potencial para serem avaliados como pesquisa.

Nesse sentido, seria necessário para o desenvolvimento do processo de seleção que o trabalho fosse de autoria de professores da educação básica, mas não só isso; que reunisse elementos comuns a um estudo investigativo, de modo que instigasse o pronunciamento dos juízes. Reconhecemos que procedemos a um préjulgamento, ele mesmo comprometido com padrões, valores, expectativas, exigências que fazem parte da cultura de pesquisa na qual estamos todos envolvidos. Estamos convencidos, porém, de que assim procedendo estamos abrindo caminho para um questionamento desses mesmos padrões, em confronto com instâncias concretas que são os exemplos escolhidos e os pareceres emitidos por avaliadores muito bem qualificados para fazê-los.

Pressupomos que os encontros científicos representavam o canal mais apropriado para a busca almejada. No conjunto de encontros da época, privilegiamos aqueles que, na sua proposta, abarcam trabalhos de professores da educação básica de todas as áreas,

${ }^{1}$ Coordenado por Menga Lüdke e vinculado ao Departamento de Educação da Pontifícia Universidade Católica do Rio de Janeiro (PUC-Rio). 
como é o caso do Encontro Nacional de Didática e Prática de Ensino (ENDIPE). Gostaríamos de poder dispor, também, de trabalhos de pesquisa realizados por professores dedicados aos diferentes domínios do currículo da educação básica. Assim, procuramos obtê-los em encontros específicos desses domínios, dentre os quais: IV Encontro sobre Investigação na Escola 2003, Centro Universitário do Vale do Taquari (UNIVATES) - Lajeado (RS); II Simpósio Internacional de Pesquisa em Educação Matemática (SIPEM 2003) - Santos (SP); XII Encontro Nacional de Ensino de Química (ENEQ 2004) - Goiânia (GO); II Congresso Mundial de Educação Ambiental 2004 - Rio de Janeiro (RJ); e XVI Simpósio Nacional de Ensino de Física (SNEF 2005) - Rio de Janeiro (RJ). Só tivemos acesso aos textos completos, além dos resumos, do ENDIPE e do SIPEM, o que limitou nosso trabalho a esses dois eventos.

O processo de análise dos trabalhos gerou um acervo de 80 textos. Uma vez completada a fase de catalogação dos textos, passamos ao exame detalhado de cada um deles. Foram leituras e releituras feitas pelo GEPROF, seguidas de análises e discussões efetuadas individualmente e nas reuniões semanais, orientadas sempre pelo alvo de encontrar trabalhos que fossem os mais próximos das atividades investigativas de um professor da educação básica, além de contar com clareza de exposição e a indicação de uma discussão teórica, ainda que incipiente, e de uma articulação metodológica mínima.

A primeira rodada de análise dos trabalhos do ENDIPE 2004 selecionou 65 textos com indicação de vinculação de seus autores com escolas de educação básica. Tais textos foram analisados detidamente por quatro integrantes do GEPROF, que indicaram 25 como possíveis trabalhos para a avaliação dos juízes. Os 25 trabalhos separados foram submetidos a novo processo de verificação sobre alguns aspectos específicos. O novo exame eliminou nove deles por representarem mais relatos de experiência, sem indicação de trabalho de pesquisa propriamente. Os 16 trabalhos remanescentes foram novamente analisados pelos integrantes do grupo, procurando fazer com que passassem por um novo crivo, decidindo-se pela seleção de apenas seis.

O levantamento dos trabalhos apresentados no Sipem 2003 foi feito com base no CD-ROM do evento, que inclui os trabalhos apresentados nos diferentes grupos de trabalho. Entre trabalhos e pôsteres, foram selecionados inicialmente todos aqueles identificados como produção de professores da educação básica. Após uma primeira leitura dos textos, foram separados 15 para uma análise mais criteriosa. O conjunto desses foi dividido entre os quatro componentes do GEPROF que já tinham feito a análise dos trabalhos do ENDIPE, visando a assegurar o desenvolvimento das mesmas etapas do processo. Após várias rodadas de análise, foram selecionados dois trabalhos para permanecerem no processo.

Com as indicações do ENDIPE e do SIPEM, tínhamos um total de oito trabalhos, o que representava, aos nossos olhos, uma tarefa ainda muito pesada para os juízes que deveriam cuidar de sua avaliação, em meio a todas as atribuições comuns a professores universitários no auge de suas carreiras acadêmicas. Depois de muitas discussões e muita reflexão dentro do grupo, decidimos que quatro seria um número aceitável para a solicitação que faríamos aos nossos avaliadores. Então, decidimos também que esses quatro deveriam ser os melhores representantes do conjunto de que dispúnhamos, o que não significa que seriam os mais representativos. Assumimos com clareza esta escolha: os quatro trabalhos selecionados foram aqueles que nós consideramos mais próximos do que se espera de um trabalho de pesquisa em educação. Acreditamos, assim, assegurar o cumprimento menos penoso e mais efetivo da delicada tarefa demandada aos nossos juízes. Para chegar aos quatro trabalhos finais, todos os integrantes do GEPROF se juntaram ao grupo dos examinadores iniciais, ajudando no processo de tomada de decisão. Chegamos, assim, aos quatro textos que consideramos os melhores exemplos de relatos sobre pesquisas realizadas por professores, dentre os cerca de 80 trabalhos recolhidos nos dois eventos. Dois deles foram extraídos do ENDIPE e dois do SIPEM; depois de eliminados os traços que 
pudessem identificar seus autores, foram enviados para a avaliação de nossos doze juízes.

As informações disponíveis nos dois encontros permitem identificar os autores como professores de instituições da educação básica, porém não trazem dados sobre sua possível participação em cursos de pós-graduação.

A preocupação com a escolha dos juízes deu-se de forma concomitante ao processo de seleção dos trabalhos. Para tentar divisar o que é considerado importante na avaliação de uma pesquisa em educação, nada melhor do que consultar quem exerce essa avaliação, em diferentes instâncias, em comitês científicos, como assessores ad hoc em comissões julgadoras, por serem reconhecidos como pesquisadores experientes e qualificados em seus respectivos domínios de interesse.

Assim, nossos juízes tinham que pertencer ao seleto grupo dos que se encontram no topo da carreira universitária, com reconhecida reputação e comprovada experiência de pesquisa e familiaridade com o sistema de avaliação empregado pelas principais fontes de financiamento, mas ao mesmo tempo deveriam irradiar abertura em relação a critérios fixos e preestabelecidos ou, pelo menos, à discussão sobre eles.

Nosso grupo de juízes é formado de 12 profissionais muito bem preparados em suas respectivas áreas de formação, com doutorado e pós-doutorado em quase todos os casos. Todos têm vasta experiência de pesquisa e intensa produção em termos de publicações, nas quais se verifica plena confirmação sobre seu interesse e sensibilidade em relação às questões da formação de professores, inclusive no que se refere à dimensão da pesquisa.

Nossa correspondência para os juízes deixava claro que os trabalhos de pesquisa foram realizados por professores da educação básica, que, entretanto, não deveriam receber uma avaliação mais flexível ou menos exigente do que a que é dirigida a qualquer trabalho de pesquisa. Queríamos o parecer de cada juiz sobre cada um dos textos enviados a partir de seu próprio julgamento, sem necessariamente se referir ou desconsiderar os critérios usados pelas várias agências financiadoras, periódicos e encontros científicos.

\section{Os trabalhos de professores e seus pareceres}

Para efeito de descrição das análises, denominaremos os trabalhos de I, II, III e IV e os juízes pelas letras alfabéticas de A até $\mathrm{K}$.

O trabalho I relata a experiência vivenciada por professores e alunos durante um processo de reformulação da proposta curricular da $5^{\mathrm{a}}$ e da $6^{\mathrm{a}}$ séries de um colégio particular, a partir do ano de 2002. O trabalho fundamenta-se em Hernández e Ventura (1998), Santomé (1998), Freire (1991), Tura (1999) e Candau (2000) para analisar o cotidiano escolar, o currículo que o constitui e a importância de uma redefinição do ensinar e aprender na perspectiva de valorização da diversidade pessoal e cultural. Os autores qualificam o trabalho como um estudo de caso focado em uma experiência de reformulação curricular. Para tanto, introduzem a discussão, contextualizando o atual cenário social, ensejando outras formas de conceber a organização do tempo e do espaço escolar e, em consequência, do seu currículo. Discutem alguns pressupostos pedagógicos apoiados em autores que estudam o cotidiano escolar e o currículo para justificar a opção por ensinar e aprender a partir do desenvolvimento de projetos de investigação. Descrevem o percurso de concepção e implementação da proposta, apontando as etapas experimentadas e os projetos trabalhados. Finalizam esboçando conquistas e desafios e ressaltando os limites e as possibilidades da caminhada percorrida. O trabalho é entendido pelos seus realizadores como sendo também uma pesquisaação, uma vez que a prática foi transformada, passando a predominar, entre os sujeitos envolvidos, a ideia de cultura reflexiva sobre a ação de ensinar e aprender.

Para boa parte de nossos juízes (oito), o trabalho em questão não pode ser considerado pesquisa. Tratase de um relato de experiência. Dos doze pareceristas, somente um confirma a sua qualificação como pesquisa-ação e dois outros consideram tratar-se de uma pesquisa, sem fazer referência ao seu tipo. Em apenas um dos pareceres identifica-se alusão à inadequação de considerar o trabalho como estudo de caso e pesquisa-ação. Em geral, o que mobiliza a análise dos avaliadores é a experiência registrada. 
É importante salientar que um relato de pesquisa é também um relato de experiência vivida. Todavia, nem toda experiência é resultante de um processo de pesquisa. No caso do trabalho em questão, o relato refere-se ao importante movimento deflagrado entre o corpo docente e a equipe dirigente de um colégio visando à reformulação curricular. O que a maioria de nossos juízes procura demarcar é que a experiência, bem-sucedida e bem relatada, tal como o registrado, não pode ser considerada mais do que um bom relato de experiência, o que é diferente de um relato de pesquisa.

No contexto da argumentação dos oito juízes que declaram que não é pesquisa, a ênfase recai sobre o conteúdo do relato. De modo geral, os pareceristas consideram que a descrição, apesar de bem redigida e fundamentada, foi feita de forma ampla e vaga, sem o necessário investimento em uma análise mais rigorosa e sistemática. A sua escrita possibilita ao leitor uma razoável visão do processo desencadeado no colégio, mas perde a consistência na medida em que não investe na problematização e nos fundamentos das decisões tomadas. Seria necessário um movimento maior em torno da construção do objeto, do problema de pesquisa, da coleta e da análise dos dados. Ater-se ao relato das etapas vividas, contextualizando e dialogando com autores que pensam currículo e cotidiano escolar não é suficiente para legitimar a experiência como trabalho investigativo. Apesar da boa fundamentação teórica presente no relato, o foco carece de maior delimitação.

Considerando ainda as análises desses oito juízes, é importante destacar que os pareceres não desmerecem possíveis sinais de pesquisa nesse trabalho. No dizer de um avaliador:

Tem conotações de pesquisa educacional? Creio que sim, porém não está relatado como pesquisa [...]. Percebe-se que todo o processo compôs-se como uma pesquisa da possível mudança curricular, porém a descrição do processo deixa claro apenas a descrição do proposto e do realizado. (Avaliador C)

Diferentemente, três dos doze pareceristas consideram o trabalho pesquisa. A justificativa elaborada por eles traz relevo ao processo desencadeado e experimentado por um grupo de professores cujo resultado evidencia produção de conhecimento novo na educação. As afirmações a seguir, extraídas dos pareceres desses três juízes, ilustram essa constatação:

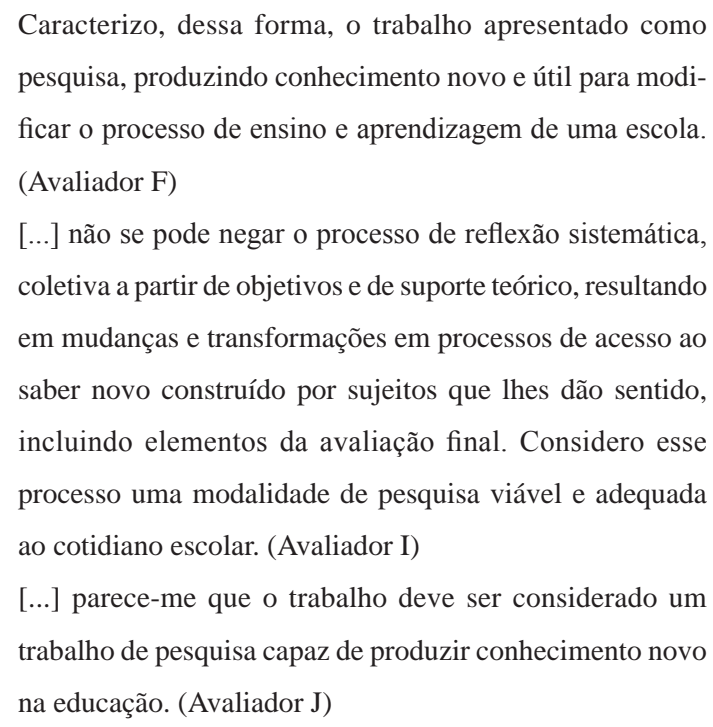

[...] parece-me que o trabalho deve ser considerado um trabalho de pesquisa capaz de produzir conhecimento novo na educação. (Avaliador J)

Para esses juízes, a produção de conhecimento representa a força motriz de um trabalho de pesquisa. Apesar de considerarem que o trabalho carece de maiores investimentos tanto na construção do objeto quanto na sua análise, o fato de se perceber nele indícios de elaboração de conhecimento o justifica como pesquisa.

Dois desses três pareceristas que tomam o trabalho como pesquisa reforçam a argumentação daqueles que o caracterizam como relato de experiência, em função da forma como o texto foi elaborado. Eles consideram que o relato, apesar de permitir a identificação de elementos essenciais a um projeto de pesquisa, padece de falta de sistematização dos dados e dos elementos de sua análise para dar suporte às conclusões. Como declara um deles,

As restrições que eu tenho referem-se à qualidade da análise. De um lado, o autor parece privilegiar as referências teóricas e focalizar de maneira limitada detalhes nos relatos; de outro lado, a interpretação do processo [...] é bastante restrita. (Avaliador J) 
O juiz que faz alusão às expressões estudo de caso e pesquisa-ação utilizadas no texto se insere entre aqueles que julgam o trabalho como relato de experiência. Embora reconheça que o texto contém diálogo com a produção intelectual na área pedagógica, possuindo inclusive características de relato científico, afirma que isso não é suficiente a um estudo para que se caracterize como pesquisa científica. Reconhece ainda que, de fato, a experiência relatada envolve um caso (a nova proposta pedagógica de um colégio) e também ênfase na ação, com vários sujeitos envolvidos no processo e experimentando a reflexão sobre a própria prática. Todavia, no seu entender, isso não parece ser suficiente para classificar o conteúdo do texto como pesquisa, seja ela do tipo estudo de caso e/ou pesquisa-ação.

O trabalho II trata do desenvolvimento da autonomia do sujeito na tomada de decisões ante situações conflitantes na área da sexualidade. Seu público-alvo são alunos da $7^{\text {a }}$ série de uma escola pública, que desenvolvem discussões a partir da intervenção da professora, motivados por uma situação do cotidiano, estabelecendo uma interação em sala de aula que, segundo as conclusões da pesquisa, favoreceria o desenvolvimento moral dos estudantes. Segundo a proposta de Josep Puig (1998) adotada no estudo, essas atividades passam pela clarificação de valores, compreensão crítica e discussão de dilemas morais.

Do conjunto de juízes, apenas três o consideram claramente como pesquisa. Para eles, o trabalho representa uma pesquisa educacional viável no contexto escolar, em função da possibilidade de estudantes se posicionarem diante de uma situação complexa a eles apresentada. O trabalho evidencia um problema sobre o qual se produz conhecimentos pela interatividade entre os alunos, professor e alunos e pesquisadora e alunos, ensejando uma reflexão sistemática e fundamentada sobre uma problemática de formação que perpassa o cotidiano escolar. Um desses três avaliadores reconhece no estudo uma proposta de intervenção fundamentada e acompanhada de reflexão avaliativa. O parecerista procura definir a sua concepção de intervenção como processo de reflexão sistemática e dialogal dos sujeitos pesquisados sob a orientação da pesquisadora professora.

Outro parecerista, que se aproxima dessa posição, apesar de afirmar que não consegue se separar dos critérios formais porque diz se basear neles para fazer os julgamentos de pesquisa, atribui ao trabalho a categorização de uma típica pesquisa do professor, o que justifica da seguinte forma:

\footnotetext{
Define uma problemática do ensino; fundamenta-se em autores da literatura educacional adequados ao problema; descreve (genericamente) os procedimentos de coleta de dados; analisa parte dos dados, tem um interesse muito local na problemática específica, não teoriza. (Avaliador A)
}

Esse juiz conclui o seu parecer revelando porque não considera esse trabalho uma pesquisa: pelo fato de o trabalho não localizar o estudo dentro de um quadro mais amplo do conhecimento já sistematizado, não conter uma descrição cuidadosa nem uma autocrítica dos métodos de coleta de dados. Nesse julgamento fica evidente o uso diferenciado do conceito de pesquisa acadêmica e pesquisa do professor, corroborando a ideia de que o parecerista admite na escola um tipo de pesquisa que se afasta dos critérios formais da academia.

Distanciando-se desses pareceres, dois outros juízes descrevem esse trabalho como relato de atividades, em que o tema está bem situado na bibliografia, embora de modo breve, sem discussões e contrapontos. Essa é uma observação recorrente na análise da maioria dos pareceristas: a falta de visão crítica no referencial teórico.

Predomina em boa parte dos juízes a consideração de que o trabalho é muito marcado pela descrição da coleta e registro de dados, sem um foco claramente delimitado. Chega-se a dizer que a conclusão ficou restrita a uma inferência genérica, que de certa forma independe dos dados, o que inviabiliza a sua indicação como uma pesquisa.

O trabalho III faz a crítica à matemática ensinada na escola. Os seus autores explicam que o problema tem suas raízes no currículo escolar disciplinar, frag- 
mentado, compartimentado e fechado. Uma alternativa que pode apontar para a superação desses problemas também é encontrada por eles na literatura (Pires, 2000; Hernández \& Ventura, 1998; Morin, 2000; Azcárate, 1997) e sintetizada como substituição do modelo tradicional por uma organização curricular mais contextualizada, em que os conhecimentos são encarados na sua complexidade e trabalhados criticamente de modo interdisciplinar. O texto passa, então, a descrever o projeto que motivou a pesquisa, relatando o trabalho realizado em três turmas de $8^{\mathrm{a}}$ série durante o ano letivo de 2001, numa escola particular. O projeto envolveu quase 100 alunos, divididos em 22 grupos, cada qual com um tema diferente escolhido pelo próprio grupo, tendo como eixo central os conhecimentos de estatística.

A maioria dos avaliadores não considera o trabalho uma pesquisa ou, pelo menos, não aceitaria o texto para publicação em periódico ou apresentação em evento científico. Entretanto, dois juízes inclinam-se por reconhecer nesse trabalho uma genuína pesquisa do professor, como afirma o juiz A. Ele destaca o fato de o trabalho estar voltado para o ensino, de ter a preocupação bem localizada na situação de ensino, sendo uma investigação da prática do ensino. O juiz I também valoriza os aspectos ligados à prática do professor e busca neles a justificativa para considerar o texto como relato de pesquisa. Em suas próprias palavras:

\footnotetext{
Pesquisa no chão da escola. Duas dimensões de pesquisa caracterizam o presente relatório. De um lado, concebido e dirigido pelo professor, um projeto de intervenção de ensinoaprendizagem fundado nos princípios epistemológicos da pesquisa. De outro, os procedimentos de levantamento, organização, análise e apresentação de dados de pesquisa, com a devida dinâmica de interação de grupos, pelos alunos envolvidos. (Avaliador I)
}

Assim, as opiniões dos juízes A e I podem ser situadas no contexto da pesquisa do professor, que vê compatibilidade entre ensino e pesquisa, uma vez que reconhece a possibilidade de construção de conhecimentos novos através da pesquisa sobre a prática docente.
A maioria dos juízes que optou por não caracterizar o trabalho como pesquisa definiu-o como relato de uma experiência escolar bem-sucedida, apesar dos problemas observados na sua estruturação. Até aqueles que o consideram pesquisa fazem ressalvas quanto ao relato. Fica claro em vários dos pareceres dos juízes que, mesmo havendo uma pesquisa de fato, é preciso melhorar seu relato, inclusive para que seja aprovada para comunicação em eventos científicos ou publicação em periódicos.

No trabalho em questão, parece ter havido grande investimento numa discussão bibliográfica, mais retórica que teórica, e pouca descrição da realidade concreta. Nessa linha vão as críticas dos juízes, que solicitam mais detalhes sobre a dinâmica da pesquisa, os impasses, os desafios, as virtudes e o que ficou sem solução.

Para o juiz $\mathrm{H}$, a natureza do objetivo proposto no trabalho é compatível com a natureza própria de um objetivo de pesquisa. No entanto, como explica o juiz F, não parece que tais objetivos sejam os colocados pelos professores-autores na sua investigação. Pelo menos pelo relato que fazem, segundo o parecerista, os objetivos enunciados referem-se ao projeto interdisciplinar que desenvolveram com os alunos na escola. Acreditamos também que vários pareceristas fizeram esforço para encontrar uma definição do problema, pois, como acontece com os objetivos, não fica claro se estamos diante do problema da pesquisa que sustentou a experiência pedagógica interdisciplinar ou se se tratava dos problemas de ordem prática que foram surgindo durante a execução do projeto.

Outro aspecto assinalado pelos juízes diz respeito ao diálogo com os conhecimentos já publicados. Os autores do trabalho trazem diversos teóricos para o debate. No entanto, a forma como trabalham com a bibliografia acaba dividindo a opinião dos avaliadores. De um lado, aqueles que vêm no artigo um relato de experiência (juízes B, F e G) consideram a abordagem teórica suficiente para tal. De outro, os que mantêm maior exigência (juízes A e J) acham que a discussão teórica feita não é suficiente para uma pesquisa que pretenda ser científica. Deduz-se 
daí que a teoria tem que ser trazida para a discussão para circunscrever e delimitar o problema, situar os conhecimentos já tidos como aceitos no campo científico, orientar as análises e mostrar os avanços alcançados com a pesquisa.

Outro problema levantado pelos juízes diz respeito às análises. Consideram que, em relação a esse trabalho, os autores criaram certas expectativas de análise que não foram atendidas pela simplicidade das reflexões que fazem ao final do texto. Eles citam as principais conclusões tiradas do processo, mas não as confrontam com a teoria que apresentam no corpo do texto. Tampouco se mostram críticos, considerando a possibilidade de tais conclusões fazerem parte da experiência prévia dos professores envolvidos ou terem surgido durante o processo, independentemente do desenvolvimento da pesquisa.

O trabalho IV apresenta um estudo que descreve e analisa, segundo a teoria dos campos conceituais de Gérard Vergnaud (1993), o modo como uma professora de matemática de uma escola pública interpretou as notações de seus alunos da $6^{\text {a }}$ série quando estes resolveram problemas de estrutura aditiva. O estudo considera duas classes de situações: aquelas para as quais o aluno dispõe das competências necessárias ao tratamento da situação e outras em que ele, por não deter todas as competências necessárias, carece de um tempo maior para refletir, explorar e fazer tentativas que poderão conduzi-lo, ou não, ao sucesso. Analisando o modo como os professores interpretam as notações produzidas por seus alunos ao resolverem problemas de estrutura aditiva, estão colocadas para o estudo as seguintes perguntas: que dificuldades os professores manifestam ao fazer tais interpretações? Eles reconhecem a presença das estruturas aditivas nos conteúdos que estão ensinando na $6^{\mathrm{a}}$ série? Embora as interpretações da professora sobre as notações de seus alunos constituam o foco principal da investigação, esse estudo baseou-se no material colhido com ambos: alunos e professora?

A experiência relatada nesse texto foi considerada uma pesquisa quase unanimemente pelos nossos juízes. Para um único juiz, G, trata-se de um relato de experiência bem consistente. Dentro das concepções desse parecerista, apesar de o texto apresentar com clareza as questões que buscou responder, elas não se apresentam formuladas cientificamente. Se assim estivessem, deveriam se mostrar comprometidas com uma universalização em seus achados, o que não está feito.

\begin{abstract}
Este trabalho mostra claramente o que estavam procurando desvendar [...]. Acho que tais questões poderiam ser consideradas como científicas se estivessem formuladas de maneira a buscar uma certa universalização em seus achados. (Avaliador G)
\end{abstract}

Então, apesar de adotar uma concepção um tanto estrita de pesquisa, esse juiz afirma a importância que atribui às experiências como um caminho de produzir melhorias e transformações das práticas a partir da construção de conhecimentos.

Para os demais juízes, trata-se de um típico trabalho de pesquisa, visto que se observam a existência de questões norteadoras, o tratamento rigoroso e meticuloso dos dados, analisados à luz do referencial teórico adotado, e o conteúdo das considerações finais, em que se percebe o compromisso realizado, de responder às questões centrais que orientaram o estudo. Quando assim se referem ao estudo, os avaliadores ressaltam, cada um a seu modo, o espírito investigativo evidente no texto. Destacam também a clareza do problema estudado e das questões e os procedimentos de coleta de dados.

Para um juiz em especial, F, essa pesquisa pode beneficiar a comunidade escolar, produzindo transformações na prática docente e favorecendo o desenvolvimento da pesquisa educacional pelos próprios professores da escola.

$\mathrm{O}$ juiz $\mathrm{H}$ considera ser esse trabalho um exemplo do que é a pesquisa científica. Segundo esse avaliador, seu relato envolve aspectos importantes: a contextualização, os procedimentos metodológicos de coleta, o tratamento das informações e suas interpretações, possibilitando, assim, o entendimento de outros pesquisadores sobre a pesquisa e suas conclusões. 


\section{Conclusão}

O estudo reuniu um importante acervo de informações, que se originou de uma ampla rede de informantes de sólida qualificação, vasta experiência de pesquisa e interesse temático diversificado, composta pelos nossos juízes. Esse acervo encontrou, por sua vez, franca acolhida no grupo de pesquisa, que, apesar da diversidade de sua composição, com estudantes de graduação, de mestrado, de doutorado e de pós-doutorado, abraçou o que poderia ser considerado quase uma bandeira, como é vista por muitos estudiosos a questão da pesquisa do professor da educação básica. Não é uma questão à qual se costuma permanecer indiferente, sendo mesmo assumida por pesquisadores americanos como um verdadeiro “movimento”, como é apontado pelas já citadas Cochran-Smith e Lytle (1999). O grupo entrou nessa corrente com entusiasmo e uma surpreendente afinidade de visões. Sem, entretanto, perder de vista a perspectiva de oferecer elementos que contribuam para esclarecer o que conta como pesquisa, em nosso caso com um esforço específico de trazer opiniões de um júri muito qualificado e bastante representativo de nossa comunidade de pesquisadores em educação.

As informações recebidas foram, portanto, sempre analisadas e consideradas peças-chave de nossa investigação e foram sendo confrontadas com ideias constantemente recolhidas junto a autores interessados em nosso tema: Beillerot (1991), André (2001), Zeichner e Nofke (2001) e Fiorentini (2004), entre outros.

Com base nas muitas discussões no grupo sobre as informações recebidas dos juízes, das muitas reflexões de cada membro em torno delas, em conjugação com as sugestões extraídas da literatura pertinente e depois de certa decantação sofrida por todo esse material trabalhado, resolvemos apontar alguns itens destacáveis de nossas análises. Não se trata de predominâncias, menos ainda de unanimidades, aspectos que não constituem preocupações primordiais das pesquisas de abordagem qualitativa. São fios condutores que perpassam o emaranhado de dados que conseguimos reunir e nos levam a certo número de traços, que consideramos esperados de uma pesquisa pelo conjunto de nossos juízes. Não são exatamente consensuais, isto é, não foram verificados por nós em todos e cada um de nossos pareceristas.

\section{Aspectos formais e de apresentação da pesquisa}

São muito valorizados os traços que se referem a uma boa apresentação geral do trabalho, tanto em relação à própria correção e adequação da linguagem quanto, e principalmente, no que tange à concatenação das ideias, à articulação entre os diferentes componentes do trabalho, de modo especial à lógica que liga o estabelecimento do problema ao desenvolvimento do estudo até as suas conclusões.

\section{Confronto entre a pesquisa realizada e seu relato}

Bastante ligado ao primeiro item, mas trazendo um aspecto importante pouco lembrado nas discussões sobre avaliação de pesquisa, o confronto entre a pesquisa e seu relato alerta para a distância que muitas vezes existe entre eles, comprometendo seriamente a possibilidade de um julgamento que faça justiça ao trabalho realizado efetivamente. Fazer bem uma pesquisa não é coisa fácil, mas é preciso também fazer bem o seu relato, o que constitui ainda maior desafio quando se trata de um texto de dimensões limitadas e formato estipulado, como é o caso, em geral, das agências financiadoras, dos encontros científicos e das publicações periódicas especializadas. A preocupação dos formadores de futuros pesquisadores dificilmente inclui essa incumbência em sua programação, como se pode notar, aliás, pela precariedade com que são feitos, em geral, os resumos das teses e dissertações.

\section{Aspectos relativos à metodologia}

Foram bastante ressaltados os problemas que comprometem o desenvolvimento do estudo desde a 
formulação do problema, passando pela proposição da amostra, dos instrumentos para a obtenção das informações, e, de modo especial, o desafio da construção dos dados, das análises efetuadas e das conclusões às quais chega o estudo. A palavra rigor foi muito evocada, assim como a preocupação com a coerência entre conclusões finais e problema ou questões iniciais.

\section{O apoio teórico}

Em três dos quatro trabalhos analisados este foi um quesito apontado como particularmente frágil. A desarticulação entre teoria e empiria foi notada por nossos juízes nos trabalhos examinados, tendo sido ressaltada de modo especial a carência do componente crítico nas análises apresentadas. Tal como notado pelos nossos pareceristas, o trabalho de tratamento dos dados, em sua articulação com a discussão teórica envolvida no estudo, é um aspecto de particular importância, que merece cuidado especial por parte dos professores formadores de futuros pesquisadores, constituindo mesmo um dos maiores desafios enfrentados pelo investigador iniciante.

Tipos de pesquisa e relação entre ensinar e pesquisar

Essa questão foi muito debatida no grupo de pesquisa, pois estamos bastante ligados à discussão levantada na literatura sobre as relações e os distanciamentos entre ensino e pesquisa, tais como são discutidos por vários autores nossos conhecidos. Devemos lembrar, a essa altura, a discussão frequente sobre a propriedade de certa pesquisa ou um tipo de pesquisa particularmente indicado para o professor, "diferente" daquele praticado pelo pesquisador da universidade. Nós, no GEPROF, temos muito receio de que essas “diferenças” que marcam a pesquisa do professor em relação à do universitário possam marcar também uma certa inferioridade ou hierarquização entre os tipos de pesquisa. E também receamos que elas possam significar uma orientação ou mesmo destinação do trabalho de pesquisa do professor para certos tipos de problemas encontrados em sua prática, o que limitaria seu trabalho de pesquisa a esses tipos de problemas e não o abririam para todos os problemas e temas que possam ser do seu interesse e, quando possível, do seu alcance.

\section{A preparação do professor para a pesquisa}

Ainda que seja um item bastante consensual, integrando já grande parte dos programas dos cursos de formação de professores (mesmo os que ainda funcionam em estabelecimentos de ensino médio) e até na própria legislação, é conveniente insistir sobre sua importância. Dedicamos a esse tema a segunda etapa do nosso estudo (Lüdke, 2002), na qual pudemos constatar as ambiguidades e dificuldades vividas por professores formadores nos cursos de licenciatura, que reconhecem a importância e a urgência da preparação do futuro professor para a prática de pesquisa. Entretanto, esse reconhecimento não basta para que percebam com clareza os caminhos mais eficientes a serem seguidos, os melhores recursos a serem empregados, o papel da monografia ou da disciplina metodologia de pesquisa. Nossos informantes, nessa etapa, mostraram-se bastante divididos em relação a essas questões, tendo, entretanto, grande convergência ao reconhecer a importância da participação do estudante em grupos de pesquisa liderados por seus professores.

É importante atentar também para o papel da formação continuada em relação a essa questão. Ainda é pouco desenvolvida entre nós a prática do envolvimento de professores da educação básica em projetos de pesquisa desenvolvidos em colaboração ou em cooperação com pesquisadores da universidade, o que representa excelente oportunidade para a preparação daqueles professores, além de propiciar condições para o desenvolvimento de pesquisas muito mais próximas e significativas para problemas da educação básica do que boa parte das que vêm sendo realizadas no meio acadêmico. Com relação a essa questão chamamos atenção especial para os trabalhos desenvolvidos por Geraldi et al. (1998), Fiorentini (2004), André (2001), 
Maldaner (2004) e Zeichner e Diniz-Pereira (2002), entre outros, e para a tese de Carvalho (2004), que analisa a contribuição de pesquisas recentemente financiadas pelo CNPq para a busca de soluções específicas para os problemas da educação básica.

\section{Pesquisa e construção de conhecimento}

Subjacente a toda a discussão em torno dos pareceres de nossos juízes, encontra-se a suposição de que a pesquisa se volta, se dedica, se define pela construção de conhecimento. É preciso atentar para a relevância que esse conhecimento tem para a área, para o domínio no qual se desenvolve o estudo, para a contribuição que seus "achados" podem oferecer no enfrentamento dos problemas vividos por alunos e professores de nossas escolas, dizem nossos juízes. Mas não questionam que a pesquisa deve consagrarse à produção de conhecimento, embora não seja, por certo, a única via para essa produção, como observou muito claramente um deles. Há outras maneiras de produzir conhecimento, lembra ele, por vezes bem mais aproximado das necessidades reais de nossa educação do que o produzido pela pesquisa.

Consideramos muito oportuno atentar para a reflexão de nosso juiz, especialmente quando estamos discutindo a complexa relação entre o professor e a pesquisa (Lüdke, 2001b). Mas também é preciso lembrar a importância que a prática de pesquisa pelo professor confere ao conhecimento por ele produzido. Sobre esse aspecto, nosso estudo pretende contribuir, com todos os seus "achados", voltados para despertar no professor - tanto o que já está atuando no magistério como o que se encontra em formação - a sua dimensão como pesquisador e a importância da preparação para ela. Nesse ponto se cruzam as necessárias discussões sobre estratégias de formação para a pesquisa, condições e recursos para a sua realização em nossas escolas, tipos e modalidades ou modos de fazer pesquisa e até sobre o próprio conceito de pesquisa, que merece bem mais questionamentos do que tem recebido, como se percebe pelo artigo muito citado de J. Beillerot (1991).

\section{Flexibilidade e abertura de nossos juízes em relação à avaliação dos trabalhos de pesquisa em educação}

Essa questão levanta uma grande e bonita discussão a partir dos dados da nossa pesquisa, pois revela o testemunho dos juízes, que são bem representativos de um conjunto muito respeitado, operoso, produtivo, reconhecido, atuante dentro da comunidade de pesquisadores em educação. Estamos usando todos esses adjetivos para lembrar o que eles representam, pois foram escolhidos justamente por reunir todas essas qualidades e outras com uma abertura para a pesquisa feita pelo professor, porém sempre atentando para princípios básicos que devem ser respeitados por qualquer pesquisa. Seus pareceres, em vários casos, mostraram clara flexibilidade, abertura e mesmo certa hesitação no uso de critérios de avaliação hoje dominantes, o que interpretamos como a possibilidade de acolhida de novos tipos de pesquisa, inclusive os praticados pelos professores das escolas, numa perspectiva de enriquecimento da própria produção de conhecimento. Isso nos anima a pensar que nosso estudo está indicando certa evolução na cultura de pesquisa dominante na área da educação.

\section{Referências bibliográficas}

ANDERSON, Gary. L.; HERR, Kathryn. The new paradigm wars: Is there room for rigorous practitioner knowledge in schools and universities? Educacional Researcher, v. 28, n. 5, p. 12-21, 1999.

ANDRÉ, Marli (org.). O papel da pesquisa na formação e na prática dos professores. Campinas: Papirus, 2001.

AZCÁRATE, Pilar Goded. Que matemáticas necesitamos para comprender el mundo atual? Investigación en la Escuela, v. 32, p. 77-86, 1997.

BEILLEROT, Jacky. La recherche: essai d'analyse. Recherche et formation. INRP, n. 9, p. 17-31, abr. 1991. Traduzido no livro de ANDRÉ, Marli. (org.). O papel da pesquisa na formação e na prática dos professores. Campinas: Papirus, 2001. p. 71-90.

CANDAU, Vera Maria F. Construir ecossistemas educativos: reinventar a escola. In: (Org.). Reinventar a escola. Petrópolis: Vozes, 2000. p. 11-16. 
CARVALHO, Merise Santos de. A pesquisa educacional sobre a escola pública de ensino fundamental, nos projetos e relatórios de pesquisa elaborados por docentes das universidades brasileiras. Tese (Doutorado em Educação) - Faculdade de Educação, Universidade Federal do Rio de Janeiro, Rio de Janeiro, 2004.

COCHRAN-SMITH, Marilyn; LYTLE, Susan. The teacher research movement: a decade later. Educacional Researcher, v. 28, n. 7, p. 15-25, out. 1999.

DINIZ-PEREIRA, Júlio Emílio; ZEICHNER, Kenneth M. (Orgs.). A pesquisa na formação e no trabalho docente. Belo Horizonte: Autêntica, 2002.

DURAND, Marc; SAURY, Jacques; VEYRUNES, Philippe. Relações fecundas entre pesquisa e formação docente: elementos para um programa. Cadernos de Pesquisa, v. 35, n. 125, p. 37-62, maio/ago. 2005.

ELLIOTT, John. Educational theory and the professional learning of teachers: an overview. Cambridge Journal of Education, v. 19, n. 1, p. 81-101, 1989.

FIORENTINI, Dario. Pesquisar práticas colaborativas ou pesquisar colaborativamente? In: BORBA, Marcelo de Carvalho; ARAÚJO, Jussara de Loiola (Orgs.). Pesquisa qualitativa em educação matemática. Belo Horizonte: Autêntica, 2004. p. 47-76.

FREIRE, Paulo. Pedagogia da autonomia. São Paulo: Paz e Terra, 1991.

GERALDI, Corinta Maria Grisolia; FIORENTINI, Dario; PEREIRA, Elisabete Monteiro A. (Orgs.). Cartografias do trabalho docente: professor(a) pesquisador(a). Campinas: Mercado das Letras/ALB, 1998.

HAMMERSLEY, Martyn. On the teacher as researcher. In: HAMMERSLEY, Martyn. (Org.). Educational Research - Current Issues. Londres: The Open University, 1993. p. 211-231.

HERNÁNDEZ, Fernando; VENTURA, Montserrat. A organização do currículo por projetos de trabalho: o conhecimento é um caleidoscópio. Porto Alegre: Artmed, 1998.

HUBERMAN, Michael; GATHER THURLER, Monica. De la recherche à la pratique: éléments de base. Berne: Peter Lang, 1991. LAGEMANN, Ellen Condliffe; SHULMAN, Lee. Issues in education research: problems and possibilities. San Francisco: Jossey-Bass Publishers, 1999.

LATHER, Patricia. Research as praxis. Harvard Educational Review, v. 56. n. 3, p. 257-277, ago. 1986.

Fertile obsession: validity after poststructuralism. Sociological quarterly, v. 34, n. 4, p. 673-693, 1993.
LÜDKE, Menga. O professor e a pesquisa. Campinas: Papirus, 2001a.

A complexa relação entre o professor e a pesquisa.

In: ANDRÉ, M. (Org.). O papel da pesquisa na formação e na prática dos professores. Campinas: Papirus, 2001b. p. 27-54.

(Coord.). A pesquisa e o professor da educação básica na visão de professores da universidade. Relatório de pesquisa. Rio de Janeiro: Departamento de Educação, PUC-Rio, 2002. .; CRUZ, Giseli Barreto da. Aproximando universidade e escola de educação básica pela pesquisa. Cadernos de Pesquisa, v. 35, n. 125, p. 81-109, maio/ago. 2005.

MALDANER, Otavio Aloisio. Ciências naturais na escola: aprendizagem e desenvolvimento. In: ROMANOWSKI, Joana Paulin; MARTINS, Pura Lúcia Oliver; JUNQUEIRA, Sérgio Rogério Azavedo (Orgs.). In: ENDIPE, 12., Conhecimento local e conhecimento universal: a aula e os campos do conhecimento, CIDADE, 2004. Anais... Curitiba: Champagnat, 2004, v. 3. p. 133-146.

MORIN, Edgar. Os sete tesouros necessários à educação do futuro. 2. ed. São Paulo: Cortez; Brasília: MEC/UNESCO, 2000.

PIRES, Célia Maria Carolina. Currículos de matemática: da organização linear à idéia de rede. São Paulo: FTD, 2000.

PUIG, Josef. M. Ética e valores: métodos para um ensino transversal. São Paulo: Casa do Psicólogo, 1998.

ROMAN, Leslie. Double exposure: the politics of feminist research. In: QUALITATIVE RESEARCH IN EDUCATION CONFERENCE. Anais... Athens: GA, 1989.

SANTOMÉ, Jurjo Torres. Globalização e interdisciplinaridade: o currículo integrado. Porto Alegre: Artmed, 1998.

STENHOUSE, Lawrence. An introduction to curriculum research and development. Londres: Heinemann, 1975.

STEVENSON, Robert. What counts as "good” action research? In: ETHNOGRAPHY IN EDUCATIONAL RESEARCH FORUM. Anais... Philadelphia: s.ed., 1996.

TARDIF, Maurice; ZOURHLAL, Ahmed. Difusão da pesquisa educacional entre profissionais do ensino e círculos acadêmicos. Cadernos de Pesquisa, v. 35, n. 125, p. 13-35, maio/ago. 2005.

TURA, Maria de Lourdes. Escola, homogeneidade e diversidade cultural. In: GONÇALVES, Maria Alice Rezende (Org.). Educação e cultura, Rio de Janeiro: Quartet, 1999. p. 87-112.

VERGNAUD, Gérard. Teoria dos campos conceituais. In: SEMINÁRIO INTERNACIONAL DE EDUCAÇÃO MATEMÁTICA DO RIO DE JANEIRO, 1., Rio de Janeiro, 1993. Anais... Rio de Janeiro: UFRJ Projeto Fundão, Instituto de Matemática, 1993. p. 1-26. 
ZEICHNER, Kenneth; NOFKE, Susan. Practitioner research. In: RICHARDSON, Virginia (Org.). Handbook of Research on Teaching. 4. ed. Washington: Aera, 2001. p. 298-330.

ZEICHNER, Kenneth; DINIZ-PEREIRA, Júlio Emílio. Pesquisa dos educadores e formação docente voltada para a transformação social. Cadernos de Pesquisa, v. 35, n. 125, p. 63-80, maio/ago. 2005.

MENGA LÜDKE, doutora em sociologia pela Universidade Paris X, com pós-doutorado na Universidade da Califórnia, Berkeley, e no Instituto de Educação da Universidade de Londres, tendo atuado como pesquisadora convidada da Universidade Jules Verne, Amiens, INRP (França), e na Faculdade de Educação da Universidade de Cambridge (Inglaterra), é professora titular da Pontifícia Universidade Católica do Rio de Janeiro (PUC-Rio), Departamento de Educação, e da Universidade Católica de Petrópolis (UCP). Na PUC-Rio coordena o Grupo de Estudos sobre a Profissão Docente (GEPROF). Publicações recentes: $O$ que conta como pesquisa? (Coord.) (São Paulo: Cortez, 2009); Ce qui compte comme recherche (Recherche et Formation, n. 59, p. 11-25, 2008); O professor e a pesquisa (Coord.) (5. ed. Campinas: Papirus, 2007); em coautoria com ANDRÉ, Marli. Pesquisa em educação: abordagens qualitativas (São Paulo: EPU, 1986); em coautoria com MEDIANO, Zélia. Avaliação na escola de $1^{\circ}$ grau: uma análise sociológica (7. ed. Campinas: Papirus, 2002). Pesquisa atual, com bolsa do Conselho Nacional de Desenvolvimento Científico e Tecnológico (CNPq) nível 1A: "O papel do curso de mestrado como primeira experiência de pesquisa para professores da educação básica”.E-mail: menga@puc-rio.br

GISELI BARRETO DA CRUZ, doutora em educação pela Pontifícia Universidade Católica do Rio de Janeiro (PUC-Rio), é professora adjunta da Faculdade de Educação da Universidade Federal do Rio de Janeiro (UFRJ). Publicações recentes: em coautoria com LÜDKE, Menga (Coord.), OLIVEIRA, Ana Teresa de Carvalho Correa de, BOING, Luiz Alberto e SCHAFFEL, Sarita Léa. O que conta como pesquisa? (São Paulo: Cortez, 2009); em coautoria com LÜDKE, Menga. Aproximando universidade e escola de educação básica pela pesquisa (Cadernos de Pesquisa, v. 35, n. 125, p. 81-109, maio/ago. 2005); com BOING, Luiz Alberto. A licenciatura em matemática e a formação do professor para a pesquisa (Presença Pedagógica, v. 12, n. 67, p. 36-46, jan./ fev. 2006); A prática docente no contexto da sala de aula frente às reformas curriculares (Educar em Revista, v. 29, p. 191-205, 2007). Integra dois grupos de pesquisa: o Grupo de Estudo sobre a Profissão Docente (GEPROF), vinculado ao Departamento de Educação da PUC-Rio, e o Grupo de Estudos e Pesquisas sobre Didática e Formação de Professores (GEPED), vinculado à Faculdade de Educação da UFRJ.E-mail: giselicruz@ufrj.br

LUIZ ALBERTO BOING, doutor em educação pela Pontifícia Universidade Católica do Rio de Janeiro (PUC-Rio), exerceu as funções de diretor geral adjunto e coordenador pedagógico do Colégio Santo Inácio, no Rio de Janeiro. Atualmente dirige o Centro Pedagógico Pedro Arrupe, dedicado a pesquisas e formação continuada dos educadores dos colégios da Associação dos Colégios Jesuítas da Província do Brasil Centro-Leste (ACOJE). Publicações recentes: em coautoria com LÜDKE, Menga (Coord.), OLIVEIRA, Ana Teresa de Carvalho Correa de, CRUZ, Giseli Barreto da e SCHAFFEL, Sarita Léa. O que conta como pesquisa? (São Paulo: Cortez, 2009) em coautoria com LÜDKE, Menga. O trabalho docente nas páginas de Educação \& Sociedade em seus (quase) 100 números (Educação \& Sociedade, v. 28, p. 1.179-1.201, out. 2007); Globalização e profissionalidade docente. A realidade brasileira (In: MOREIRA, Antonio Flavio; PACHECO, José Augusto (Org.). Globalização e educação: desafios para políticas e práticas. Porto: Porto Editora, 2006. p. 127-166); Caminhos da profissão e da profissionalidade docentes (Educação \& Sociedade, v. 25, p. 1.159-1.180, set./dez. 2004). Integra o Grupo de Estudo sobre a Profissão Docente (GEPROF), vinculado ao Departamento de Educação da PUC-Rio.E-mail: lula@ pedroarrupe.com.br

Recebido em maio de 2008 Aprovado em maio de 2009 
movimientos sociales; pedagogía de la alternancia; libertad y emancipación.

André Luiz Paulilo

As estratégias de administração das políticas públicas de educação na cidade do Rio de Janeiro entre 1922 e 1935

$\mathrm{O}$ artigo busca explanar as estratégias de administração da educação pública desenvolvidas na cidade do Rio de Janeiro entre 1922 e 1935. Examinando as políticas públicas de educação, durante as administrações de Antônio Carneiro Leão (1922-1926), Fernando de Azevedo (1927-1930) e Anísio Teixeira (1931-1935), apresenta as mudanças ocorridas na organização da Diretoria Geral de Instrução Pública. Na complexa rede de instituições e saberes, visando reformar a estrutura administrativa da educação, a ampliação das agências de Estado e a especialização dos serviços de educação constituem um importante recurso político.

Palavras-chave: políticas públicas de educação; reforma educacional; escolarização 1922-1935; história da educação.

\section{The administrative strategies for public policies of education in the city of Rio de escolaridad 1922-1935; historia de la educación.} Janeiro between 1922 and 1935

This article seeks to explain the administrative strategies for public education developed in the city of Rio de Janeiro between 1922 and 1935. A careful look at the public policies of education, during the administrations of Antônio Carneiro Leão (1922-1926), Fernando de Azevedo (1927-1930) and Anisio Teixeira (1931-1935), shows the changes in the organization of the General Directorate of Public Instruction in the Federal District. The amplification of state agencies and the specialization of educational services constitute an important political resource in the complex network of institutions and knowledge, aimed at reforming the administrative structure of education.
Key words: public policies of education; educational reform; schooling 19221935; history of education.

Las estrategias de administración de las políticas públicas de educación en la ciudad de Rio de Janeiro entre 1922 y 1935

El artículo busca explicar las estrategias de administración de la educación pública desarrolladas en la ciudad de Rio de Janeiro entre 1922 y 1935. Examinando las politicas públicas de educación, durante la administración de Antônio Carneiro Leão (1922-1926), Fernando de Azevedo (1927-1930) y Anísio Teixeira (1931-1935), presenta los cambios ocurridos en la organización de la Directoria General de Instrucción Pública. En la compleja red de instituciones y saber, enfocando la reforma de la estructura administrativa de la educación, la ampliación de las agencias de Estado y la especialización de los servicios de educación constituyen un importante recurso político.

Palabras claves: políticas públicas de educación; reforma educacional;

Menga Lüdke, Giseli Barreto da Cruz e Luiz Alberto Boing

A pesquisa do professor da educação básica em análise

O texto discute a pesquisa do professor com autores que veem nela alguma possibilidade de acontecer. Dentre os autores trabalhados, destacam-se: Stenhouse, Elliott, Huberman, Geraldi, Fiorentini, Cochran-Smith, Lytle, Anderson, Herr, André, Lüdke, Cruz, Zeichner, Diniz-Pereira, Nofke, Tardif e Zourhlal. Para servir de instrumento à pesquisa, foram selecionados dois trabalhos de professores que foram apresentados no XII Encontro Nacional de Didática e Prática de Ensino (ENDIPE,
2004) e dois outros no II Seminário Internacional de Pesquisa em Educação Matemática (SIPEM, 2003). Os quatro textos foram enviados a 12 juízes, escolhidos em diferentes instâncias, dentre profissionais bem preparados em suas respectivas áreas de formação, com vasta experiência de pesquisa e intensa produção, além de interessados e sensibilizados com a formação de professores, inclusive no que se refere à sua pesquisa. A partir dos pareceres desses avaliadores, são apresentados alguns resultados teórico-metodológicos e práticos que podem enriquecer o debate sobre os limites e possibilidades da pesquisa dos professores.

Palavras-chave: pesquisa educacional; professor da educação básica; julgamento.

\section{Primary school teacher research under appraisal}

The text discusses teacher research with writers who perceive the possibility of this kind of research taking place. Among these writers we highlight: Stenhouse, Elliott, Huberman, Geraldi, Fiorentini, Cochran-Smith, Lytle, Anderson, Herr, André, Lüdke, Cruz, Zeichner, Diniz-Pereira, Nofke, Tardif e Zourhlal. As research tools, two papers presented by teachers at the XII Encontro Nacional de Didática e Prática de Ensino (ENDIPE, 2004) and two other papers presented at the II Seminário Internacional de Pesquisa em Educação Matemática (SIPEM, 2003) were selected. The four texts were sent to twelve judges chosen at different instances among well-reputed professionals in their respective areas of expertise, with considerable research experience and impressive academic production. The selected judges had also shown interest and understanding of teacher training, including teacher research. Based on the written views of these evaluators some theoreticalmethodological as well as practical results are presented that might 
contribute to enrich the debate on the limits and possibilities of teacher research.

Key words: educational research; primary education teachers; evaluation.

\section{La pesquisa del profesor de la} educación básica en análisis El texto discute la pesquisa del profesor con autores que ven en ella alguna posibilidad de ocurrir. Entre los autores trabajados, se destacan : Stenhouse, Elliott, Huberman, Geraldi, Fiorentini, Cochran-Smith, Lytle, Anderson, Herr, André Lüdke, Cruz, Zeichner, Diniz-Pereira, Nofke, Tardif y Zourhlal. Para servir de instrumento a la pesquisa, fueron seleccionados dos trabajos de profesores que fueron presentados en el XII Encontro Nacional de Didática e Prática de Ensino (ENDIPE, 2004) y otros dos en el II Seminário Internacional de Pesquisa em Educação Matemática (SIPEM, 2003). Los cuatro textos fueron enviados a 12 jueces, escogidos en diferentes instancias, entre profesionales bien preparados en sus respectivas áreas de formación, con una gran experiencia de pesquisa e intensa producción, además de interesados y sensibilizados con la formación de profesores, inclusive lo referente a su pesquisa. A partir de los pareceres de esos evaluadores, son presentados algunos resultados teóricos metodológicos y prácticos que pueden enriquecer el debate sobre los límites y posibilidades de la pesquisa de los profesores.

Palabras claves: pesquisa educacional; profesor de la educación básica; juzgamiento.

Gilberto Luiz Alves e Carla Villamaina Centeno

A produção de manuais didáticos de história do Brasil: remontando às origens (1838-1889)
O artigo decorre de um programa de pesquisa que investiga o papel dos instrumentos do trabalho didático na relação educativa. Elege como foco o discurso dos manuais didáticos de história do Brasil e, para aprofundar a análise do conteúdo, procura apreender as interpretações acerca da Guerra da Tríplice Aliança (1864-1870). Prioriza manuais didáticos pioneiros, produzidos no período imperial, a exemplo de Lições de história do Brazil, de Joaquim Manuel de Macedo, um dos principais compêndios da área no Colégio Pedro II. Esses manuais, quanto à concepção pedagógica e à forma de organização, comportavam incipiente simplificação e objetivação do trabalho didático que denotavam os primeiros indícios de uma organização técnica de base manufatureira.

Palavras-chave: história da educação; trabalho didático; manuais didáticos; história do Brasil; Guerra da Tríplice Aliança.

\section{The production of textbooks on the} history of Brazil: returning to the origins (1838-1889)

This article derives from a research programme investigating the role of teaching instruments in the educational relation. It selects as its focus the discourse of textbooks on the history of Brazil and, to sharpen its analysis of the content, it seeks to apprehend the interpretations of the War of the Triple Alliance (1864-1870). It prioritizes pioneering textbooks, produced in the imperial period, following the example of Lessons on the history of Brazil, by Joaquim Manuel de Macedo, one of the most important works on the subject used at the Pedro II College. With regard to their pedagogical conception and form of organization, these textbooks revealed an incipient simplification and objectification of educational work that denoted the first signs of technical organization of a manufacturing base.
Key words: history of education; educational work; textbooks; history of Brazil; War of the Triple Alliance.

La producción de manuales didácticos de historia de Brasil: remontando a los orígenes (18381889)

El presente trabajo resulta de un programa de investigación que trata del papel de los instrumentos de trabajo didáctico en la relación educativa. Elige como foco el discurso de los manuales didácticos de historia de Brasil y, para profundizar el análisis del contenido, busca aprehender las interpretaciones respecto a la Guerra de la Triple Alianza (1864-1870). Prioriza manuales didácticos pioneros, producidos en el período imperial, a ejemplo de Lições de história do Brasil, de Joaquim Manuel de Macedo, uno de los principales compendios del área en el Colégio Pedro II. Esos manuales, en cuanto a la concepción pedagógica y a la forma de organización, presentaban incipiente simplificación y objetivación del trabajo didáctico, que denotaban los primeros rasgos de una organización técnica de base manufacturera.

Palabras claves: historia de la educación; trabajo didáctico; manuales didácticos; historia de Brasil; Guerra de la Triple Alianza.

Geisa Magela Veloso

Imprensa e Escola Normal: representações de progresso e civilização na produção de um imaginário social - 1918-1938 Tomando elementos da história de Montes Claros, no estado de Minas Gerais, como referência, discute-se a utilização dos conceitos de representação, apropriação e prática (Chartier, 1990, 2001, 2002) e de imaginário social (Baczko, 1985), no contexto da história cultural. Confere-se visibilida- 